\title{
Comparison of the Socialization Levels of Secondary School Students In Terms of Some Variables
}

\section{Alp Eren Aydin ${ }^{1}$ Nuri Topsakal ${ }^{2}$ Nurper Ozbar ${ }^{\circledR}$}

'Duzce University, Institute of Health Sciences, Department of Physical Education and Sports, Duzce, Turkey. ${ }^{2}$ Email:alperrenaydin@gmail.com Tel: +905069351112

${ }^{2,3}$ Duzce University, Faculty of Sport Sciences, Duzce, Turkey.

Email:topsakal.nuri@gmail.com Tel: +90544308250s

${ }^{5}$ Email: nurperozbar@gmail.com Tel: +905376661620

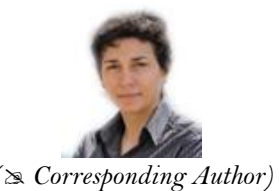

\section{Abstract}

This study was carried out to compare the socialization levels of secondary school students in terms of some variables. Data were obtained from secondary school students $(\mathrm{n}=565)$ studying in a province in western Turkey. "Socialization Scale" and "Socialization in Sports Scale" developed by Sahan (2007) were used as data collection tools. The reliability coefficient of the socialization scale was 0.77 , and the reliability coefficient of the socialization in sports scale was 0.84 . Descriptive statistics, Kolmogorov Smirnov test, Mann Whitney U test, and Kruskal Wallis test were used to analyze the data. As a result of the analysis, there were no differences in the socialization levels of the students in terms of age, licensed sports year, and sports branch variables $(p>0.05)$, while a significant difference was found in the gender variable $(p<0.05)$. Significant differences were observed in the socialization level of the students in terms of the class variable $(p<0.05)$ and the father's educational status variable $(\mathrm{p}<0.01)$. A significant difference was found at the level of $\mathrm{p}<0.01$ in the socialization, and the level of socialization in sports at the $\mathrm{p}<0.05$ level of the students in terms of the mother's educational status variable. In terms of the frequency of doing sports, a significant difference was observed at the $p<0.05$ level in the socialization of students in sports.

Keywords: Education, Socialization, Sports, Sports background Secondary school, Student.

Citation | Alp Eren Aydin; Nuri Topsakal; Nurper Ozbar (2020). Comparison of the Socialization Levels of Secondary School Students In Terms of Some Variables. Asian Journal of Education and Training, 6(4): 583-591.

History:

Received: 10 July 2020

Revised: 17 August 2020

Accepted: 21 September 2020

Published: 1 October 2020

Licensed: This work is licensed under a Creative Commons

Attribution 3.0 License $(\mathrm{cc})$ E

Publisher: Asian Online Journal Publishing Group
Acknowledgement: All authors contributed to the conception and design of the study.

Funding: This study received no specific financial support

Competing Interests: The authors declare that they have no conflict of interests.

Transparency: The authors confirm that the manuscript is an honest, accurate, and transparent account of the study was reported; that no vital features of the study have been omitted; and that any discrepancies from the study as planned have been explained.

Ethical: This study follows all ethical practices during writing.

\section{Contents}

1. Introduction

2. Method

584

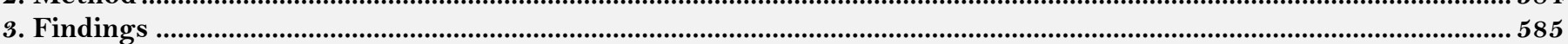

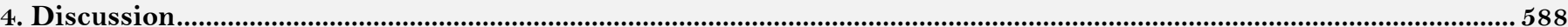

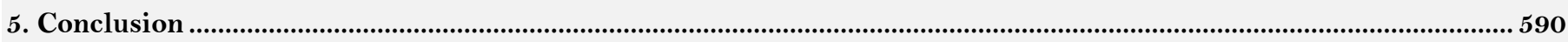

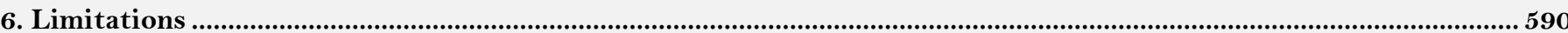

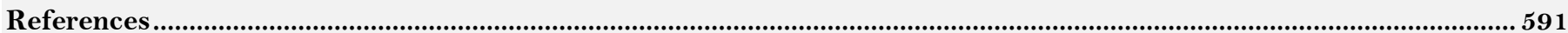




\section{Contribution of this paper to the literature}

Sport helps social values, which are of great importance in society, to be formed and sustained on individuals, provides a space for individuals to socialize, and also contributes to their psycho-social development. Considering these positive contributions of sports, our study aimed to contribute to the literature by comparing the socialization levels of middle school students in terms of some variables.

\section{Introduction}

Sport is one of the key elements in today's modern societies that enable people to develop mentally, emotionally, and physically, facilitate teamwork, and ensure cooperation and solidarity. In addition to providing various physical activities, sport is a phenomenon that provides people with personal and social status, adds a sense of belonging to a group, and also helps the socialization process of the individual.

Sport helps social values, which are of great importance in society, to be formed and sustained on individuals, provides a space for individuals to socialize, and also contributes to their psycho-social development. Socialization ensures that culture is passed down from generation to generation and that people comply with social norms determined in social life. In this context, socialization can be expressed as one of the main elements that constitute the individual's personality and self (Kucuk \& Koc, 2013). People grow up with physical activities and games that reflect the cultural values of their society since childhood. Playing and physical activities provide individuals with an awareness of their role, rules, and norms, and contribute to the development of a person's skills, emotional structure, and personality traits. In addition, the person has the ability to communicate and cooperate with the environment and other people. Especially organized sports make a significant contribution to the social and personal development of individuals. Considering all these, sports can be considered as one of the effective activities in the socialization process (Bulgu \& Akcan, 2003). The socialization process starts from the birth of the person and continues throughout life. Adolescence and childhood are the years of first and long-term socialization. Socialization reveals cultural phenomena and values, knowledge, attitudes, and behaviors related to the models that a person will take place in society (Berber, 2011). In order for a person to socialize in a positive way, some functions must occur together. These can be considered as knowledge, repetition, social support, and reactions of others (Ozkalp, 2005). Sport is a socialization tool that has entered the social life in various ways, directly or indirectly connected to people, and has managed to attract the attention of society. Sports, which makes people dependent on themselves by meeting the indispensable pleasures, demands, and needs of the society, has become an important socialization tool in today's modern societies (Caha, 1999). When socialization is considered as a means of developing behavior in accordance with the values of the society in which the individual lives, sports are seen as an indispensable element for the individual to shape himself. Especially the use of sports in education at schools is very important in terms of ensuring the development of students. Sports contribute a lot to the shaping and development of students' personality (Inel, 1996). One of the most important functions of sports is to create a feeling of belonging to a group in individuals. The feeling of belonging is one of the important values for a person in the socialization process. Sport has an important place in creating a sense of belonging to the nation, family, and team, in achieving a certain status in the society, and in the formation of the role that the individual takes. Success in the field of sports will contribute to the increase of the feelings mentioned and the socialization of individuals (Ozdinç, 2005).

Based on the above information, this study aimed to compare the socialization levels of secondary school students in terms of some variables. In this context, answers to the following research questions were sought:

$R Q$ 1. Are there significant differences in the "socialization" and "socialization in sports" levels of the students in terms of the age variable?

$R Q$ 2. Are there significant differences in the "socialization" and "socialization in sports" levels of the students in terms of the gender variable?

$R Q$ 3. Are there significant differences in the "socialization" and "socialization in sports" levels of the students in terms of the class variable?

$R Q 4$. Are there significant differences in the "socialization" and "socialization in sports" levels of the students in terms of the mother's educational status variable?

$R Q$ 5. Are there significant differences in the "socialization" and "socialization in sports" levels of the students in terms of the father's educational status variable?

$R Q$ 6. Are there significant differences in the "socialization" and "socialization in sports" levels of the students in terms of the licensed sports year variable?

$R Q 7$. Are there significant differences in the "socialization" and "socialization in sports" levels of the students in terms of the sports branch variable?

$R Q$ 8. Are there significant differences in the "socialization" and "socialization in sports" levels of the students in terms of the frequency of doing sports variable?

\section{Method}

\subsection{Research Purpose}

The purpose of this study is to compare the socialization levels of licensed secondary school students in sports according to variables such as age, gender, class, mother's educational status, father's educational status, licensed sports year, sports branch, and frequency of doing sports.

\subsection{Sample Size}

The sample of this study consists of licensed students who study at four secondary schools in the central district of Duzce Province, Turkey. A simple random sampling method was used in the study, and 565 students who volunteered to participate for the study were reached. The characteristics of the sample group according to some variables are shown in Table 1. 
Table-1. Frequency and percentage distributions of students according to some variables.

\begin{tabular}{|c|c|c|c|}
\hline Variables & Categories & $f$ & $\%$ \\
\hline \multirow[t]{5}{*}{ Age } & 11 & 165 & 29.2 \\
\hline & 12 & 122 & 21.6 \\
\hline & 13 & 117 & 20.7 \\
\hline & 14 & 161 & 28.5 \\
\hline & Total & 565 & 100 \\
\hline \multirow{3}{*}{ Gender } & Female & 225 & 39.8 \\
\hline & Male & 340 & 60.2 \\
\hline & Total & 565 & 100 \\
\hline \multirow{5}{*}{ Class } & 5 & 151 & 26.7 \\
\hline & 6 & 145 & 25.7 \\
\hline & 7 & 114 & 20.2 \\
\hline & 8 & 155 & 27.4 \\
\hline & Total & 565 & 100 \\
\hline \multirow[t]{5}{*}{ Mother's educational status } & No education & 9 & 1.6 \\
\hline & Primary/Secondary & 248 & 43.9 \\
\hline & Lycee & 207 & 36.7 \\
\hline & University & 101 & 17.8 \\
\hline & Total & 565 & 100 \\
\hline \multirow{5}{*}{ Father's educational status } & No education & 6 & 1.1 \\
\hline & Primary/Secondary & 160 & 28.3 \\
\hline & Lycee & 255 & 45.1 \\
\hline & University & 144 & 25.5 \\
\hline & Total & 565 & 100 \\
\hline \multirow{5}{*}{ Licensed sports year } & $1-2$ & 367 & 64.9 \\
\hline & $3-4$ & 151 & 26.8 \\
\hline & $5-6$ & 42 & 7.4 \\
\hline & More than 7 & 5 & 0.9 \\
\hline & Total & 565 & 100 \\
\hline \multirow{3}{*}{ Sports branch } & Team sports & 361 & 63.8 \\
\hline & Individual sports & 204 & 36.2 \\
\hline & Total & 565 & 100 \\
\hline \multirow{6}{*}{ Frequency of doing sports } & Every weekday & 140 & 24.8 \\
\hline & Three days a week & 184 & 32.5 \\
\hline & Only weekends & 69 & 12.2 \\
\hline & Sometimes & 96 & 17.1 \\
\hline & Others & 76 & 13.4 \\
\hline & Total & 565 & 100 \\
\hline
\end{tabular}

Note: $f=$ Frequency; $\%=$ Percentage

Table 1 shows the distribution of 565 licensed sports students in terms of various variables.

\subsection{Measurement Instrument}

As data collection tools, the "Socialization Scale" and "Socialization in Sports Scale" developed by Sahan (2007) were used to determine the socialization levels of students in sports. The first part of the scale form consists of personal and demographic information, the second part is a 34-item socialization scale, and the third part is a 35 -item socialization in sports scale. Original reliability values of the scale reflect 0.77 for socialization scale and 0.84 for socialization in sports scale. More than 0.70 is considered reliable in terms of social sciences.

\subsection{Statistical Analysis}

Frequency and percentage were used in the descriptive statistics of the data. Normality tests of the scales were performed using the Kolmogorov Smirnov test. Since the data are not normally distributed, nonparametric tests were applied. Mann Whitney U test was used to compare two groups, and the Kruskal Wallis test was applied to compare three or more groups. Mann Whitney $\mathrm{U}$ test was used to make pairwise comparisons in groups with differences. The level of significance in the statistical results of the data was accepted as 0.05.

\section{Findings}

In this section, there are findings related to group differences in the socialization levels of students within variables such as age, gender, class, mother's educational status, father's educational status, licensed sports year, sports branch, and frequency of doing sports. Problem questions (RQ) are given below and the results of the tests applied to determine whether there is a significant difference between the variables are presented.

RQ1: Are there significant differences in the "socialization" and "socialization in sports" levels of the students in terms of the age variable? The results of the Kruskal Wallis test conducted to find an answer to the question are shown in Table 2.

In terms of socialization, no difference was found between the groups according to the Kruskal Wallis test results of the age variable $\left(X^{2}=6.790 ; \mathrm{Sd}=3 ; \mathrm{p}>0.05\right)$. Similarly, no difference also was found between the groups regarding socialization in sports $\left(\right.$ father $\left.^{2}=2.376 ; \mathrm{Sd}=3 ; \mathrm{p}>0.05\right)$, Table 2 .

RQ2: Are there significant differences in the "socialization" and "socialization in sports" levels of the students in terms of the gender variable? The results of the Mann Whitney U test conducted to find an answer to the question are shown in Table 3. 


\begin{tabular}{|c|c|c|c|c|c|c|}
\hline$\overline{\text { Scales }}$ & Age & $\mathbf{N}$ & Mean Rank & SD & $X^{2}$ & $\mathbf{P}$ \\
\hline \multirow{5}{*}{ Socialization } & 11 & 165 & 268.72 & \multirow{5}{*}{3} & \multirow{5}{*}{6.790} & \multirow{5}{*}{0.079} \\
\hline & 12 & 122 & 266.36 & & & \\
\hline & 13 & 117 & 313.57 & & & \\
\hline & 14 & 161 & 288.03 & & & \\
\hline & Total & 565 & & & & \\
\hline \multirow{5}{*}{ Socialization in sports } & 11 & 165 & 279.97 & \multirow{5}{*}{3} & \multirow{5}{*}{2.376} & \multirow{5}{*}{0.498} \\
\hline & 12 & 122 & 269.59 & & & \\
\hline & 13 & 117 & 301.45 & & & \\
\hline & 14 & 161 & 282.85 & & & \\
\hline & Total & 565 & & & & \\
\hline
\end{tabular}

Note: ${ }^{\mathrm{p}}>0.05$.

Table-3. Comparison of socialization levels of students according to the gender variable.

\begin{tabular}{|c|c|c|c|c|c|c|}
\hline$\overline{\text { Scales }}$ & Gender & $\overline{\mathbf{N}}$ & Mean Rank & Sum of Ranks & $\overline{\mathbf{U}}$ & $\bar{P}$ \\
\hline \multirow{3}{*}{ Socialization } & Female & 225 & 300.67 & 67650.00 & \multirow{3}{*}{34275.000} & \multirow{3}{*}{$0.036^{*}$} \\
\hline & Male & 340 & 271.31 & 92245.00 & & \\
\hline & Total & 565 & & & & \\
\hline \multirow{3}{*}{ Socialization in sports } & Female & 225 & 300.47 & 67606.00 & \multirow{3}{*}{34319.000} & \multirow{3}{*}{$0.038^{*}$} \\
\hline & Male & 340 & 271.44 & 92289.00 & & \\
\hline & Total & 565 & & & & \\
\hline
\end{tabular}

Table 3 shows that there are significant differences between the groups in the gender variable in terms of socialization according to the results of the Mann Whitney $U$ test $(\mathrm{U}=34275.000$; $p<0.05)$. Similarly, there are significant differences between the groups in terms of socialization in sports in the gender variable $(\mathrm{U}=34319.000$; $\mathrm{p}<0.05)$.

RQ3: Are there significant differences in the "socialization" and "socialization in sports" levels of the students in terms of the class variable? The results of the Kruskal Wallis test and Mann Whitney U test conducted to find an answer to the question are shown in Table 4.

\begin{tabular}{|c|c|c|c|c|c|c|c|}
\hline Scales & Class & $\mathbf{N}$ & Mean Rank & SD & $X^{2}$ & $\mathbf{P}$ & Significant difference \\
\hline \multirow{5}{*}{ Socialization } & $5^{\text {th }}$ & 151 & 263.39 & \multirow{5}{*}{3} & \multirow{5}{*}{9.893} & \multirow{5}{*}{$0.019^{*}$} & \multirow{5}{*}{$\begin{array}{l}5^{\text {th }}-7^{\text {th }} \text { Class } \\
6^{\text {th }}-7^{\text {th }} \text { Class }\end{array}$} \\
\hline & $6^{\text {th }}$ & 145 & 265.60 & & & & \\
\hline & $7^{\text {th }}$ & 114 & 319.25 & & & & \\
\hline & $8^{\text {th }}$ & 155 & 291.72 & & & & \\
\hline & Total & 565 & & & & & \\
\hline \multirow{5}{*}{ Socialization in sports } & 5 & 151 & 268.37 & \multirow{5}{*}{3} & \multirow{5}{*}{5.233} & \multirow{5}{*}{0.156} & \\
\hline & 6 & 145 & 272.79 & & & & \\
\hline & 7 & 114 & 311.17 & & & & \\
\hline & 8 & 155 & 286.09 & & & & \\
\hline & Total & 565 & & & & & \\
\hline
\end{tabular}

Table 4 indicates that there are significant differences between the groups in the Kruskal Wallis test results of the class variable in terms of socialization $\left(X^{2}=9.893 ; \mathrm{SD}=3 ; \mathrm{p}<0.05\right)$. Mann Whitney $\mathrm{U}$ test was applied to determine among which classes the socialization scores were significant. According to the test results, there was no significant difference between 5th and 6th grades $(\mathrm{U}=10848.500 ; \mathrm{p}>0.05)$, 5th and 8th grades $(\mathrm{U}=10569.500$; $\mathrm{p}>0.05)$, 6th and 8th grades $(\mathrm{U}=10166.500 ; \mathrm{p}>0.05)$, and 7 th and 8th grades $(\mathrm{U}=7982.500 ; \mathrm{p}>0.05)$. However, there were significant differences between the 5th and 7 th grades $(\mathrm{U}=6878.000 ; \mathrm{p}<0.05)$ and 6 th and 7 th grades $(\mathrm{U}=6714.500 ; \mathrm{p}<0.05)$. On the other hand, there are no significant differences between the groups in the Kruskal Wallis test results of the class variable in terms of socialization in sports $\left(X^{2}=5.233 ; \mathrm{Sd}=3 ; \mathrm{p}>0.05\right)$.

RQ4: Are there significant differences in the "socialization" and "socialization in sports" levels of the students in terms of the mother's educational status variable? The results of the Kruskal Wallis test and Mann Whitney U test conducted to find an answer to the question are shown in Table 5.

\begin{tabular}{|c|c|c|c|c|c|c|c|}
\hline Scales & Mother's educational status & $\mathbf{N}$ & Mean Rank & SD & $X^{2}$ & $\mathbf{P}$ & Significant difference \\
\hline \multirow{5}{*}{ Socialization } & No education & 9 & 214.22 & \multirow{5}{*}{3} & \multirow{5}{*}{22.188} & \multirow{5}{*}{$0.000^{*}$} & \multirow{5}{*}{$\begin{array}{c}\text { No-Uni } \\
\text { P/S-Uni } \\
\text { Hs-Uni }\end{array}$} \\
\hline & Primary/Secondary $(\mathrm{P} / \mathrm{S})$ & 248 & 260.36 & & & & \\
\hline & High school $(\mathrm{Hs})$ & 207 & 281.62 & & & & \\
\hline & University (Uni) & 101 & 347.55 & & & & \\
\hline & Total & 565 & & & & & \\
\hline \multirow{5}{*}{$\begin{array}{l}\text { Socialization } \\
\text { in sports }\end{array}$} & No education & 9 & 213.00 & \multirow{5}{*}{3} & \multirow{5}{*}{8.414} & \multirow{5}{*}{$0.038^{* *}$} & \\
\hline & Primary/Secondary $(\mathrm{P} / \mathrm{S})$ & 248 & 271.62 & & & & $\mathrm{P} / \mathrm{S}-$ Uni \\
\hline & High school (Hs) & 207 & 281.05 & & & & Hs-Uni \\
\hline & University (Uni) & 101 & 321.17 & & & & \\
\hline & Total & 565 & & & & & \\
\hline
\end{tabular}

Note: ${ }^{*} \mathrm{p}<0.01{ }^{* *} \mathrm{p}<0.05$

Table 5 indicates that there are significant differences between the groups in the Kruskal Wallis test results of the mother's educational status variable in terms of socialization $\left(X^{2}=22.188 ; \mathrm{SD}=3 ; \mathrm{p}<0.01\right)$. Mann Whitney $\mathrm{U}$ test 
was applied to determine among which the educational status the socialization scores were significant. According to the test results, there was no significant difference between "no education" and "primary/secondary education" levels $(\mathrm{U}=912.000 ; \mathrm{p}>0.05)$. Similarly, there was no significant difference between "no education" and "high school education" levels ( $\mathrm{U}=706.500 ; \mathrm{p}>0.05)$. There was a significant difference between "no education” and "university" levels (U=264.500; $<<0.05$ ). There was no significant difference between "primary/secondary education" and "high school education" levels ( $\mathrm{U}=23700.000$; p $>0.05$ ). There was a significant difference between "primary/secondary education" and "university" levels ( $U=8672.500 ; \mathrm{p}<0.05)$. There was a significant difference between "high school education" and "university" levels (U=7975.500; $\mathrm{p}<0.05)$.

Table 5 also shows that there are significant differences between the groups in the Kruskal Wallis test results of the mother's educational status variable in terms of socialization in sports $\left(X^{2}=8.414 ; \mathrm{SD}=3\right.$; $\left.\mathrm{p}<0.05\right)$. Mann Whitney $\mathrm{U}$ test was applied to determine among which the educational status the socialization in sports scores were significant. According to the test results, there was no significant difference between "no education" and "primary/secondary education" levels ( $\mathrm{U}=884.500 ; \mathrm{p}>0.05)$. There was no significant difference between "no education" and "high school education" levels ( $U=707.000 ; p>0.05$ ). There was no significant difference between "no education" and "university" levels ( $U=280.500 ; \mathrm{p}>0.05$ ). There was no significant difference between "primary/secondary education" and "high school education" levels (U=23700.000; p $>0.05$ ). There was a significant difference between "primary/secondary education" and "university" levels $(\mathrm{U}=10336.500 ; \mathrm{p}<0.05)$. There was a significant difference between "high school education" and "university" levels (U=8960.000; $p<0.05)$.

RQ5: Are there significant differences in the "socialization" and "socialization in sports" levels of the students in terms of the father's educational status variable? The results of the Kruskal Wallis test and Mann Whitney U test conducted to find an answer to the question are shown in Table 6.

\begin{tabular}{|c|c|c|c|c|c|c|c|}
\hline Scales & $\begin{array}{l}\text { Father's educational } \\
\text { status }\end{array}$ & $\mathbf{N}$ & $\begin{array}{l}\text { Mean } \\
\text { Rank }\end{array}$ & SD & $X^{2}$ & $\mathbf{P}$ & $\begin{array}{c}\text { Significant } \\
\text { difference }\end{array}$ \\
\hline \multirow{5}{*}{ Socialization } & No education & 8 & 161.25 & & & & \\
\hline & Primary/Secondary $(\mathrm{P} / \mathrm{S})$ & 160 & 255.30 & & & & No-Uni \\
\hline & High school (Hs) & 254 & 283.61 & 3 & 13.210 & $0.004^{*}$ & $\mathrm{P} / \mathrm{S}-$ Uni \\
\hline & University (Uni) & 143 & 314.08 & & & & \\
\hline & Total & 565 & & & & & \\
\hline \multirow{5}{*}{$\begin{array}{l}\text { Socialization in } \\
\text { sports }\end{array}$} & No education & 8 & 226.42 & & & & \\
\hline & Primary/Secondary $(\mathrm{P} / \mathrm{S})$ & 160 & 267.80 & & & & \\
\hline & High school (Hs) & 255 & 280.60 & 3 & 4.274 & 0.233 & \\
\hline & University (Uni) & 142 & 302.86 & & & & \\
\hline & Total & 565 & & & & & \\
\hline
\end{tabular}

Table 6 indicates that there are significant differences between the groups in the Kruskal Wallis test results of the father's educational status variable in terms of socialization $\left(X^{2}=13.210 ; \mathrm{SD}=3 ; \mathrm{p}<0.01\right)$. Mann Whitney $\mathrm{U}$ test was applied to determine among which the educational status the socialization scores were significant. According to the test results, there was no significant difference between "no education" and "primary/secondary education" levels $(\mathrm{U}=330.000 ; \mathrm{p}>0.05)$. Similarly, there was no significant difference between "no education" and "high school education" levels $(\mathrm{U}=414.500$; $\mathrm{p}>0.05)$. There was a significant difference between "no education" and "university" levels $(\mathrm{U}=202.500 ; \mathrm{p}<0.05)$. There was no significant difference between "primary/secondary education" and "high school education" levels (U=18214.500; $>>0.05)$. There was a significant difference between "primary/secondary education" and "university" levels $(\mathrm{U}=9123.000 ; \mathrm{p}<0.05)$. There was no significant difference between "high school education" and "university" levels $(\mathrm{U}=16118.000 ; \mathrm{p}>0.05)$.

Table 6, on the other hand, indicates that there is no significant difference between the groups in the Kruskal Wallis test results of the father's educational status variable in terms of socialization in sports $\left(X^{2}=4.274 ; \mathrm{Sd}=3\right.$; $\mathrm{p}<0.01)$.

RQ6: Are there significant differences in the "socialization" and "socialization in sports" levels of the students in terms of the licensed sports year variable? The results of the Kruskal Wallis test conducted to find an answer to the question are shown in Table 7.

Table-7. Comparison of socialization levels of students according to the licensed sports year variable.

\begin{tabular}{|c|c|c|c|c|c|c|}
\hline Scales & Licensed sports year & $\mathbf{N}$ & Mean Rank & SD & $X^{2}$ & $\mathbf{P}$ \\
\hline \multirow{5}{*}{ Socialization } & $1-2$ & 367 & 278.26 & \multirow{5}{*}{3} & \multirow{5}{*}{1.687} & \multirow{5}{*}{0.640} \\
\hline & $3-4$ & 151 & 294.83 & & & \\
\hline & $5-6$ & 41 & 281.78 & & & \\
\hline & More than 7 & 5 & 227.40 & & & \\
\hline & Total & 564 & & & & \\
\hline \multirow{5}{*}{ Socialization in sports } & $1-2$ & 367 & 278.42 & \multirow{5}{*}{3} & \multirow{5}{*}{2.518} & \multirow{5}{*}{0.472} \\
\hline & $3-4$ & 151 & 296.89 & & & \\
\hline & $5-6$ & 41 & 275.00 & & & \\
\hline & More than 7 & 5 & 208.80 & & & \\
\hline & Total & 564 & & & & \\
\hline
\end{tabular}

In terms of socialization, no difference was found between the groups according to the Kruskal Wallis test results of the licensed sports year variable $\left(X^{2}=1.687 ; \mathrm{SD}=3 ; \mathrm{p}>0.05\right)$. Similarly, no difference also was found between the groups regarding socialization in sports $\left(X^{2}=2.518 ; \mathrm{SD}=3 ; \mathrm{p}>0.05\right)$, Table 7 . 
RQ7: Are there significant differences in the "socialization" and "socialization in sports" levels of the students in terms of the sports branch variable? The results of the Kruskal Wallis test conducted to find an answer to the question are shown in Table 8.

Table-8. Comparison of socialization levels of students according to the sports branch variable

\begin{tabular}{|c|c|c|c|c|c|c|}
\hline Scales & Sports branch & $\mathbf{N}$ & Mean Rank & SD & $X^{2}$ & $\mathbf{P}$ \\
\hline \multirow{8}{*}{ Socialization } & Football & 169 & 263.36 & \multirow{8}{*}{6} & \multirow{8}{*}{8.322} & \multirow{8}{*}{0.215} \\
\hline & Basketball & 55 & 263.29 & & & \\
\hline & Volleyball & 128 & 310.47 & & & \\
\hline & Handball & 9 & 268.06 & & & \\
\hline & Gymnastics & 15 & 264.97 & & & \\
\hline & Athletics & 37 & 264.84 & & & \\
\hline & Other & 151 & 294.15 & & & \\
\hline & Total & 564 & & & & \\
\hline \multirow{8}{*}{ Socialization in sports } & Football & 169 & 269.72 & \multirow{8}{*}{6} & \multirow{8}{*}{4.737} & \multirow{8}{*}{0.537} \\
\hline & \begin{tabular}{|l|} 
Basketball \\
\end{tabular} & 55 & 291.71 & & & \\
\hline & Volleyball & 128 & 296.50 & & & \\
\hline & Handball & 9 & 233.06 & & & \\
\hline & Gymnastics & 15 & 300.47 & & & \\
\hline & Athletics & 37 & 312.73 & & & \\
\hline & Other & 151 & 275.34 & & & \\
\hline & Total & 564 & & & & \\
\hline
\end{tabular}

In terms of socialization, no difference was found between the groups according to the Kruskal Wallis test results of the sports branch variable $\left(X^{2}=8.322 ; \mathrm{SD}=6 ; \mathrm{p}>0.05\right)$. Similarly, no difference also was found between the groups regarding socialization in sports $\left(X^{2}=4.737 ; \mathrm{Sd}=6\right.$; $\left.\mathrm{p}>0.05\right)$, Table 8 .

RQ8: Are there significant differences in the "socialization" and "socialization in sports" levels of the students in terms of the frequency of doing sports variable? The results of the Kruskal Wallis test and Mann Whitney U test conducted to find an answer to the question are shown in Table 9.

Table-9. Comparison of socialization levels of students according to the frequency of doing sports variable.

\begin{tabular}{|c|c|c|c|c|c|c|c|}
\hline Scales & Frequency of doing sports & $\mathbf{N}$ & Mean Rank & SD & $X^{2}$ & $\mathbf{P}$ & $\begin{array}{c}\text { Significant } \\
\text { difference }\end{array}$ \\
\hline \multirow{6}{*}{ Socialization } & Every weekday & 140 & 295.64 & \multirow{6}{*}{4} & \multirow{6}{*}{7.458} & \multirow{6}{*}{0.114} & \\
\hline & Three days a week & 184 & 275.28 & & & & \\
\hline & Only weekends & 69 & 243.31 & & & & \\
\hline & Sometimes & 95 & 280.79 & & & & \\
\hline & Others & 75 & 310.15 & & & & \\
\hline & Total & 563 & & & & & \\
\hline \multirow{6}{*}{$\begin{array}{l}\text { Socialization in } \\
\text { sports }\end{array}$} & Every weekday & 140 & 310.65 & \multirow{6}{*}{4} & \multirow{6}{*}{11.033} & \multirow{6}{*}{$0.026^{*}$} & \multirow{6}{*}{$\begin{array}{l}\text { A-B } \\
\text { A-C } \\
\text { B-D } \\
\text { D-C }\end{array}$} \\
\hline & Three days a week & 184 & 264.17 & & & & \\
\hline & Only weekends & 69 & 266.17 & & & & \\
\hline & Sometimes & 95 & 262.53 & & & & \\
\hline & Others & 75 & 311.47 & & & & \\
\hline & Total & 563 & & & & & \\
\hline
\end{tabular}

Table 9 indicates that there is no significant difference between the groups in the Kruskal Wallis test results of the frequency of doing sports variable in terms of socialization $\left(X^{2}=7.458 ; \mathrm{SD}=4 ; \mathrm{p}>0.05\right)$. However, there are significant differences between the groups in the Kruskal Wallis test results of the frequency of doing sports variable in terms of socialization in sports $\left(X^{2}=11.033 ; \mathrm{Sd}=4 ; \mathrm{p}<0.05\right)$. Mann Whitney $\mathrm{U}$ test was applied to determine among which frequency of time level the socialization scores were significant. According to the test results, there was significant difference between "every weekday" and "three days a week" levels $(\mathrm{U}=10767.000 ; \mathrm{p}<0.05)$. There was no significant difference between "every weekday" and "only weekends" levels ( $U=4082.000 ; p>0.05)$. There was significant difference between "every weekday" and "sometimes" levels $(\mathrm{U}=5488.500 ; \mathrm{p}<0.05)$. There was no significant difference between "every weekday" and "others" levels (U=5239.000; $>>0.05)$. There was no significant difference between "three days a week" and "only weekends" levels (U=6286.000; p >0.05). There was no significant difference between "three days a week" and "sometimes" levels ( $\mathrm{U}=8684.000 ; \mathrm{p}>0.05)$. There was significant difference between "three days a week" and "others" levels $(U=5739.000 ; \mathrm{p}<0.05)$. There was no significant difference between "only weekends" and "sometimes" levels (U=3272.500; $>>0.05)$. There was no significant difference between "only weekends" and "others" levels $(\mathrm{U}=2176.500 ; \mathrm{p}>0.05)$. There was significant difference between "others" and “sometimes" levels (U=2935.500; $\mathrm{p}<0.05)$.

\section{Discussion}

This study was carried out to compare the socialization levels of secondary school students in terms of some variables such as age, gender, class, mother's educational status, father's educational status, licensed sports year, sports branch, and frequency of doing sports.

According to the findings of the age variable in our study, there was no significant difference between the groups in the levels of "socialization" and "socialization in sports". According to this result, it can be said that the age variable does not have a determining effect on the "socialization" and "socialization in sports" levels of the students who do sports. The fact that the age groups of the students participating in the study are close to each other may have been effective in the emergence of such a result. In the literature, there are researches that support the findings 
in our study (Karaca, 2012; Merter, 2013) as well as researches that do not (Erdoğdu, 2018; Gök, 2016; Yıldız, 2015). When the researches in the literature are examined, Merter (2013) which had one of the similar studies, did not find any statistically significant difference between the group averages of social-emotional learning skills of secondary school students. 206 students participated in the study of (Karaca, 2012) titled "examining the personal adaptation and socialization levels of athletes in middle education institutions". According to the results of the study, no significant difference was observed between age levels. Researches that differ from the result of our study are as follows. Erdoğdu (2018) in his study, found that the communication skills of the youth in the 17-20, 21-24, and 25-28 age groups according to the age variable were higher than the young people in the 13-16 age group. Gök (2016) in his study involving students aged 16-17-18, observed that socialization levels increased as the age of the participants increased. Yildız (2015) in his study, found that the socialization levels of students under the age of 19 were lower than those of 20-22 and 23-25. The author also observed that the socialization levels of students over 26 were lower than those of other age groups. Further, it has been observed that as the age increases, students' ability to do sports and their frequency of doing sports increases, thus contributing significantly to the socialization levels of the students.

The levels of "socialization" and "socializing in sports" of the female students participating in our study were found to be significantly higher than the male students. According to this result, it can be said that the gender variable has a significant effect on the socialization and sports socialization levels of the students who participated in the study. This difference seen in our study is thought to be due to the developmental characteristics of female students and the fact that girls are more present in social environments than male students. Gender differences are directly related to early adolescence, maturing, and developing relations with the environment in this period, affecting the socialization levels as a result of communication, these periods when children are in question. It is more common for children to interact more with their environment during this period and to be less affected by this change through sports and mood swings. There are other studies in the literature that support this finding obtained in our study (Altınköprü, 2001; Dodson, 2007; Duran, Celiköz, \& Topaloğlu, 2013; Ocal \& Kamerkaya, 2014; Ozcan \& Yildırım, 2011; Sahan, 2007). In this context, when the studies are examined, Dodson (2007) argues that females have faster social development compared to males, mature earlier, and are more compatible than males. Altınköprü (2001) found in his study that females have a higher level of cooperation and socialization tendency compared to males. In addition, the author observed that males tend to be lonelier than females, and, at a 50-minute observation period, on average, females chose 20 minutes of loneliness and males chose 33 minutes of loneliness.

Duran et al. (2013) observed in their studies on middle school students that females have higher socialization levels than males. Sahan (2007) in his study to find the role of sports activities in the socialization process of university students, reported that the socialization level of females was higher than males. Ocal and Kamerkaya (2014) in their study on secondary school students staying in orphanages, reported that female students had higher social skill levels than male students. Similarly, Kandir and Orçan (2011) observed that girls perform better than boys in social skills in all age groups. Ozcan and Ylldırım (2011) found in their studies to compare the social skill levels of secondary school students, they found a significant difference in favor of female students between those who are licensed team sports and individual sports and those who do not do sports. In addition, Chaplin, Cole, and ZahnWaxler (2005) found that females are more obedient and exhibit less maladaptive behaviors than males.

Our study indicated that the grade level variable had a significant effect on students' socialization levels, but not on socialization in sports. The findings of our study showed that the socialization level of seventh-grade students was higher than the fifth and sixth-grade students. Accordingly, it can be said that the higher the class level, the higher the socialization level. However, it was determined that there was no significant difference between the socialization levels of the seventh and eighth-grade students, and the average of the seventh-grade students was higher. According to this result, it can be said that the LGS exam negatively affects the socialization levels of eighth-grade students. It can be said that the reasons such as the students in the eighth grade focusing on the success of the exam for the education at the next level, increasing their studying hours, and having anxiety of failure in the exam have a decreasing effect on their level of socialization. In the literature review on the subject, we came across the research of Duran et al. (2013) related to determining the social skill levels of middle school students, including 5th, 6th, 7th, and 8th-grade students. In this study, as the grade level increased, the socialization level of the students decreased, but this result is not consistent with our study. This may be due to differences in variables such as physical and psychological environment, socio-economic level, environmental factors, and parents' education levels of the secondary schools. Erdimez (2016) in his study on physical education and sports students in a university, found that there was no statistically significant difference between sports and socialization levels according to the class variable. According to the results of this research, the class variable does not affect the level of sports and socialization and therefore does not coincide with the results of our study. This result may be due to the difference between the age levels of the students in both studies and the fact that the students in the other study received training on sports at their school. Aytan (2010) in his study, examined the socialization status of the students attending the first and upper classes in secondary education and found that there was no difference between them. Considering that the age of the students will increase as the class levels increase, it can be said that the age difference in secondary education does not affect socialization. Therefore, this study does not coincide with our study.

The findings of our study showed that the levels of students" "socialization" and "socialization in sports" differ significantly according to the education level of the mother. Accordingly, as mothers' educational status increase, students' levels of "socialization" and "socialization in sports" also increases. The socialization levels of students whose mothers are university graduates are higher than those whose mothers are illiterate and graduated from primary/secondary and high school. In addition, students whose mothers are university graduates have higher levels of socialization in sports than those whose mothers are primary/secondary and high school graduates. Among the reasons for this situation, because mothers are more cultured and more conscious, directing their children to social environments, encouraging their children to be in such environments, and directing their children to sports. There are different studies in the literature that support this finding we obtained in our study. In one of these studies, Sahan (2007) found in his study to determine the role of sports activities in the socialization process of university students, that the education level of parents directly affects socialization in sports. Sunay and Saracaloğlu (2003) determined in their study that there is a relationship between family support and participation in sports. In a study conducted in 15 
sports branches and 551 athletes, the family variable ranked first in the order of the factors that encourage sports. It has also been found that the family plays a very important role in encouraging children to do sports (Donuk, Balcıŏlu, Senduran, \& Ulker, 2003).

In the study, the socialization levels of students in socialization and sports differ significantly according to the father's education variable. Sahan (2007) in his study to find out the role of sports activities in the socialization process of university students, found that the education level of parents directly affects socialization in sports. According to the results of our study, the reason why there was a significant difference in terms of the educational level of the father is that as the education level of the father increases, the socialization of children in sports increases to a higher level. As a result, in families with a high level of education, children are more consciously encouraged to do sports, so they socialize in a shorter time.

The results of our study showed that the variable of years of doing sports with a license does not have a significant effect on the "socialization" and "socialization in sports" levels of the students. In this study, because the age groups are at the secondary school level, there is little difference between the licensed years of the students. For this reason, there may not have been a significant difference in the "socialization" and "socialization in sports" levels of the students in terms of the variable of doing sports with a license. Ozcan and Yıldırım (2011) found a significant difference between the groups in terms of licensed year variable in their studies, so this result supports our study.

Our study indicated that the sports branches of the students with license did not cause a significant difference in their "socialization" and "socialization in sports" levels. The results of Car (2018) study covering the secondary school level are not similar to our study. When $\mathrm{p}<0.05$ values of wrestling, athletics, and football branches are considered, it is seen that they are less than alpha value. In other words, students who are interested in wrestling, athletics, and football have higher socialization levels. It was observed that there was a significant difference in the opinion scores of the students for socialization according to the branches. The reasons why the results of this study do not overlap with our study may be due to factors such as secondary school, environmental conditions, differences in educators, and family.

Our study showed that the frequency of students doing sports does not affect their "socialization" levels and does not create significant differences in their "socialization in sports" levels. Students who do sports every day during the week have a higher level of "socializing in sports" compared to other students. According to this result, it can be said that being more in sports environments and therefore interacting with people such as coaches, athletes, teammates (cooperating, communicating verbally and non-verbally, determining common goals, etc.) causes higher rates of socialization in students. This result of the study is similar to the study by Konca, Ermiş, Erilli, Kaplan, and Berk (2018). Konca et al. (2018) concluded that as the duration of students' doing sports increases, individuals become more social and do not have difficulty in relating to their environment.

\section{Conclusion}

In summary, as a result, no significant difference was observed in the socialization levels of students in socialization and sports in terms of the age variable. In the gender variable, significant differences were found both in the "socialization" levels and "socialization in sports" levels of students. In the class variable, only significant differences were observed in the socialization levels of the students. In the mother's educational status variable, significant differences were observed in both the "socialization" levels and the "socialization in sports" levels of the students. In the father's educational status variable, a significant difference was found only in the socialization levels of the students. According to the licensed sports year variable, there was no significant difference in the "socialization" levels and "socialization in sports" levels of the students. Similarly, in the sports branch variable, there was no significant difference in the "socialization" levels and "socialization in sports" levels of the students. Finally, in the frequency of doing sports variable, only a significant difference was observed in the "socialization in sports" levels of students.

\subsection{Suggestions}

Based on the findings of our study, the following suggestions can be given:

- Our study indicated that students who were licensed in sports had a high level of socialization in sports. Therefore, sports competitions between classes can be organized within the school to increase the level of socialization of students who do not do sports with a license. In addition, students can be encouraged to do sports in inter-school competitions as licensed.

- Our study showed that as the education level of parents increased, "socialization" levels and "socialization in sports" levels of the students also increased. Therefore, in order to raise the awareness of parents, various seminars can be organized by experts to inform about the benefits of sports and socialization at school, and students can be encouraged to do sports.

- Guidance services can be provided to eighth-grade students, especially by experts. Thus, it can be aimed to reduce the exam anxiety of the students and increase their level of socialization by directing them to sports.

- Students should be directed to sports branches according to their interests and skills. For this, students can be guided through personality inventories and test applications specific to various sports branches.

- Various social environments can be created to increase the socialization level of male students at least as much as female students. By providing team spirit among students, their collaboration and solidarity can be increased.

\section{Limitations}

This study is limited to the students' answers to the scale questions applied in the study and the students studying in state secondary schools in the fall semester of the 2018/2019 academic year in Duzce, Turkey. 


\section{References}

Altınköprü, T. (2001). Toung girl psychology and sexuality. Istanbul: Hayat Yayıncllık.

Aytan, G. K. (2010). Effects of sports on secondary school students' socialization. Gazi University, Institute of Educational Sciences, Doctorate Thesis, Ankara.

Berber, R. (2011). The effect of sports on the socialization of the hearing impaired. Dumlupinar University, Institute of Health Sciences, Master Thesis, Kütahya.

Bulgu, N., \& Akcan, F. (2003). Sports and Socialization, Physical education and social Fields Congress in Sports

Ankara: Gazi University Sports High School Publications.

Caha, O. (1999). Taking a breath by leaning on sports. Ankara: Beta Publishing.

Car, H. (2018). Investigation of the effects of physical education lesson on socialization of middle school and imam-hatip middle school students. Gazi University, Master Thesis, Ankara.

Chaplin, T. M., Cole, P. M., \& Zahn-Waxler, C. (2005). Parental socialization of emotion expression: Gender differences and relations to child adjustment. Emotion, 5(1), 80-88. Available at: https://doi.org/10.1037/1528-3542.5.1.80.

Dodson, F. (2007). Children's education handbook. Istanbul: Ravza Publications.

Donuk, B., Balcığlu, İ., Senduran, F., \& Ulker, I. (2003). Psychosocial and demographic characteristics of 14-16 age group young basketball athletes living in Istanbul. Paper presented at the 10th İCHBER-SD European Congress and SBD 8th International Sports Sciences Congress , 17-20 November, Antalya.

Duran, G., Celiköz, N., \& Topaloğlu, A. (2013). Determining the social skill levels of secondary school students. Inönü University, Journal of Education Faculty, $14(2), 121-137$.

Erdimez, A. (2016). Examination of physical education and sports college students' socialization levels with sports according to different variables. Sütçü İmam University, Master Thesis, Kahramanmaras.

Erdoğdu, M. (2018). Examining the socialization levels and communication skills of young people who benefit from leisure time organizations Necmettin Erbakan University, Institute of Health Sciences, Master's Thesis.

Gök, M. (2016). Examining the socialization levels of students who do active sports and do not do sports in secondary education. Gazi University, Master Thesis, Ankara.

Inel, M. (1996). How central is sport in identity formation? , Mersin University, Institute of Social Sciences, Physical Education and Sports Department, Master Thesis, Mersin.

Kandir, A., \& Orçan, M. (2011). A comparative analysis of early learning skills and social adaptation and skills of 5-6 year old children. Ilkogretim Online, $10(1), 40-50$.

Karaca, Y. (2012). Examining the personal adaptation and socialization levels of sports students in secondary education institutions. Gazi University, Master Thesis, Ankara.

Konca, E., Ermiş, E., Erilli, N., Kaplan, A., \& Berk, Y. (2018). Comparison of personality traits of middle school students who do sports and those who do not. Cross Section Academy Journal, 4(13), 379-438.

Kucuk, V., \& Koc, H. (2003). Relationship between human and sports in psychosocial develpoment process. Dumlupinar University, Journal of Social Sciences, 9, $211-222$.

Merter, K. (2013). Investigation of the relationship between secondary school students' social emotional learning skills and self-esteem Yeditepe University, Institute of Social Sciences, Master's Thesis, Istanbul.

Ocal, A., \& Kamerkaya, G. (2014). Investigation of socialization skills of 6 th - 8th grade students living in orphanages. K. $\ddot{U}$. Kastamonu Education Journal, 23 (4), 1567-1584.

Ozcan, G., \& Yıldırım, S. (2011). Comparison of the social skill levels of the students who do team sports and individual sports as licensed and the Students Who Do Not Do Sports. Bolu Abant İzet Baysal University Journal of the Institute of Social Sciences, 11(2), $111-135$.

Ozdinç, O. (2005). Çukurova University students 'views on the relationship between sports and participation in sports with socialization. Spormetre Physical Education and Sports Sciences Journal, 3(2), 77-84.

Ozkalp, E. (2005). Introduction to behavioral sciences (pp. 77-115-117). Eskisehir: Anadolu University Open Education Publications.

Sahan, H. (2007). The role of sports activities in the socialization process of University students. Selçuk University, Institute of Social Sciences, PhD Thesis, Konya.

Sunay, H., \& Saracaloğlu, A. S. (2003). The expectations of Turkish athletes from sports and the elements that direct them to sports. Spormetre Physical Education and Sports Sciences Journal, 1(1), 43-48.

Yıldız, Y. (2015). Examining the socialization and happiness levels of university students who do sports and not do sports. Muğla Sitkı Kocaman University, Institute of Health Sciences, Master Thesis, Muğla. 